\title{
Risco sistêmico e a histeria gerada no mercado financeiro global
}

\author{
SYSTEMIC RISK AND THE HYSTERIA GENERATED IN \\ THE GLOBAL MARKET \\ * Thalles Alexandre Takada \\ ** Tânia Lobo Muniz
}

* Mestre em Direito Negocial pela Universidade estadual de Londrina - UEL, Especialista em Direito Internacional e Econömico - UEL, Graduado em Ciëncias Econômicas UEL, em Direito Pitágoras, Advogado, Coordenador da Comissão de Direito Digital da OAB Subseção Londrina. E-mail: thallestakada@gmail.com

** Graduação em Direito pela Universidade Estadual de Londrina (1988), mestrado em Direito pela Pontifícia Universidade Católica de São Paulo (1997) e doutorado em Direito pela Pontifícia Universidade Católica de São Paulo (2004). Atualmente é professora associada da Universidade Estadual de Londrina. E-mail: lobomuniz@gmail.com

Resumo: Os arranjos negociais ordenados por uma ordem econômica voltada a abastecer o mercado financeiro criam uma fragilidade inerente ao próprio sistema. Essa fragilidade é reflexo da tomada de decisão dos indivíduos mediante às vicissitudes socioeconômicas surgidas nesse mercado. Simples notícias divulgadas podem desencadear uma crise sistêmica. Essa é a proposição que o presente artigo investiga, ou seja, quais fatores econômico-jurídicos que podem causar e controlar os efeitos drásticos na economia, sendo a chamada corrida aos bancos o mais visível desses fenômenos. Utilizando-se de teorias econômicas aliadas à doutrina jurídica, demonstra-se de maneira interdisciplinar que a sociedade não é uma matriz quadrada de fatores lineares, mas um complexo sistema de intercâmbios negociais regidos pela (ir)racionalidade humana.

Palavras-chave: Risco sistêmico. Histeria financeira. Crise de 1929, Mercado financeiro. Direito e economia.

Abstract: The negotiating arrangements ordered by an economic order focused to supply the financial market creates an inherent weakness to the system itself. This weakness reflects the decision taking of individuals through the socioeconomic events arising in this market. Simple news reports may trigger a systemic crisis. The present article investigates this proposition, in other words, which economic and legal factors can cause and control the drastic effects on the economy, like the bank run the most visible of these phenomena. Using economic theories related to legal doctrine, it shows up in an interdisciplinary way that society is not a square matrix of linear factors, but a complex system of negotiation exchange governed by the human (ir)rationality.

Keywords: Systemic risk. Financial hysteria. 1929 crisis. Financial market. Law and economics. 


\section{INTRODUÇÃO}

A conjectura econômica internacional é formada por uma estrutura complexa de instituições que operam em diversos países, quase que simultaneamente. A globalização, trazida pelas novas tecnologias da informação, possibilitou a essas instituições funcionarem sem que a consideração dos elementos espaço e tempo fosse necessário.

Nesse contexto, o mercado financeiro, talvez o mal (necessário?) de todos os tempos, é a mais volátil forma de movimentar fortunas e as fazer desaparecer. Ambiente em que se verifica o objeto dessa análise, a denominada histeria, que compreende o comportamento gerado quando uma informação é divulgada e uma "população" de consumidores corre aos bancos para sacar seus depósitos.

Questiona-se: O que ocasiona esse comportamento? A economia explica? Os governos são responsáveis? Amplas são as discussões acerca do tema sem se chegar a um consenso.

Para tentar responder a essas perguntas, necessário faz-se entender a estrutura bancária e divagar pelas teorias comportamentais da economia, entender os fatores causadores da histeria no sistema financeiro internacional (geradora da falência de diversas instituições financeiras) demonstrando que o sistema jurídico existente, especificamente, a parte que concerne ao mercado financeiro, é fragilmente criado, dando a possibilidade que a histeria financeira ocorra, e se o Estado, como agente interventor, poderia utilizar meios delineados pelo Direito, para atenuar os efeitos das crises geradas.

Difícil precisar qual o fator desencadeia uma crise no sistema financeiro. Não haveria uma regra para explicar esses fenômenos, devido ao grande número de instituições, países, políticas diversas e interesses privados. Contudo, pretendese demonstrar que é possível apreender esses elementos, a partir da análise de alguns modelos teóricos que explicam a atuação desses fatores, e mostrar que a história, com suas transformações sociais, é o maior laboratório de pesquisa para o entendimento dos sistemas econômico e jurídico.

Assim, o trabalho inicia com um exemplo, o mais notório de todos os tempos, poder-se-ia dizer, encetada no berço do capitalismo mundial, no símbolo da fartura e da riqueza de Wall Street, que foi a crise de 1929.

Após uma visão geral da crise financeira de 1929, demonstra-se, de maneira breve, a estrutura do sistema financeiro, servindo de base para entender aquele comportamento criado no sistema financeiro internacional. Por meio da 
econômica comportamental tenta-se expor a histeria por intermédio das teorias do efeito cascata, efeito manada e cascata de disponibilidades, em que cada teoria é representada por modelos econômicos com casos pertinentes.

$\mathrm{Na}$ sequência, distanciando-se um pouco das teorias comportamentais da economia, o trabalho aborda alguns aspectos jurídicos de controle econômico, sendo as políticas estatais ou os tratados. Demonstra-se que o Estado e os institutos de direito internacional têm a capacidade de inibir ou controlar os efeitos da crise financeira e discute-se quais políticas podem ser utilizadas para que tais consequências não ocorram ou sejam controladas.

São cada vez mais comuns as crises financeiras derivadas do alto risco sistêmico em que o sistema normativo interno e internacional propicia, no sentido da grande liberdade que os agentes desse mercado possuem para manipular e criar os ativos financeiros. Assim, o trabalho traz uma discussão acerca da fragilidade do sistema financeiro internacional e da sua necessidade de controle. Demonstrando que os instrumentos normativos do direito internacional são imprescindíveis para ressalvar esse sistema e para que a parte mais fraca, que são os cidadãos dos países, não sofram as piores consequências dessas crises.

\section{A CRISE DE 1929}

Em 1929 o mundo viu milhares de pessoas perderem seu patrimônio, suicídios de empresários falidos, filas de famintos e muitas outras mazelas sociais. A economia foi submetida a um círculo vicioso em que a superprodução levou a uma baixa geral de preços, falência de indústrias, queda das ações, falências bancárias, diminuição do crédito, desemprego e, consequentemente, ao subconsumo.

Trotski (1936) expõe o cenário:

A crise de 1929-1933 e a evolução ulterior forneceram confirmação abundante do bem fundado desta apreciação. No país mais rico do mundo, a renda total dos trabalhadores da indústria e da agricultura foi literalmente amputada pela metade entre 1929 e 1932. De dois milhões, o número de desempregados elevou-se a 18 ou 20 milhões. A produção de aço foi reduzida a menos de $20 \%$ da sua capacidade. As exportações, que ultrapassavam os cinco bilhões de dólares, mal chegavam a 1,5 bilhão; as importações passaram de quatro bilhões e meio para cerca de um bilhão. Depois de 4.600 falências bancárias em três anos, todos os bancos do país fecharam seus guichês em março de 1933 no apogeu da crise financeira. 
O terror criado pela crise de 1929 foi historicamente estrondoso, seus danos perduraram por alguns anos mais, como Trotski descreveu. Todavia, o desencadear da crise foi antecedido por um sistema complexo envolvendo a produção e o mercado financeiro. John Kenneth Galbraith $(2009$, p. 2) relata que o período que antecedeu a grande crise foi próspero, os índices de produção e emprego estavam altos. Entre 1925 e 1929, o numero de fábricas aumentaram de 183.900 para 206.700; o valor de sua produção do setor subiu de $\$ 60,8$ para $\$ 68$ bilhões de dólares. A produção de automóveis em 1926 foi de 4.301 .000 de unidades, e três anos mais tarde foi mais de 5.700.000.

Essa euforia produtiva que se passava nos Estados Unidos foi, para muitos, o que levou à Grande Depressão. Após a Primeira Guerra Mundial a Europa estava devastada e carente de alimentos e produtos industrializados. Os Estados Unidos foi o principal fornecedor desses produtos por um longo período. Ocorre que a Europa foi se reconstruindo e necessitando menos de produtos vindos dos Estados Unidos, em contrapartida o parque industrial dos Estados Unidos aumentou expressivamente conforme relatou Galbraith. O ano de 1929 foi o estopim, com uma produção muito grande e um consumo baixo, o que levou a um período de deflação e, consequentemente, à falência de empresas. Em 24 de outubro de 1929, dia conhecido como Quinta-Feira Negra, as ações da Bolsa de Nova York caíram drasticamente. Ou seja, da noite para o dia os ativos financeiros perderam abruptamente seus valores, o dinheiro desapareceu, e junto com eles a renda de milhões de cidadãos.

O que se seguiu depois disso foi uma histeria financeira, os depositantes correram aos bancos para sacarem seus depósitos cujos bancos não possuíam os valores para devolver, acarretando a falência de vários deles. Mas para entender como isso ocorreu, é necessário compreender, a grosso modo, como funciona a estrutura do sistema financeiro.

\section{ESTRUTURA DO SISTEMA FINANCEIRO}

O mercado financeiro é composto de diversas instituições financeiras, como Bancos Comerciais, Bancos Múltiplos, Bancos de Investimento, Sociedades de Crédito e Financiamentos, entre outros. Todas essas instituições são consideradas intermediadoras financeiras. Para que esse sistema exista é necessária a figura de dois agentes: os tomadores de empréstimos e os poupadores. 
Dentre as instituições financeiras, a de maior relevância para o presente trabalho são as bancárias (ou monetárias), as quais podem captar depósitos à vista e usar esses recursos como empréstimos ou financiamento para pessoas físicas ou jurídicas.

Krugman (2008) explicita que os bancos existem porque conseguem conciliar o conflito entre os tomadores e os poupadores. Poupadores querem liberdade, ter acesso ao seu dinheiro de curto prazo. Os tomadores querem comprometimento, eles não querem risco de enfrentar demandas súbitas de reembolso. E explica:

Normalmente, os bancos satisfazem ambos os desejos: os depositantes têm acesso aos seus fundos sempre que quiserem, mas a maior parte do dinheiro colocado aos cuidados de um banco é usada para fazer empréstimos de longo prazo. A razão pela qual isso funciona é que as retiradas são geralmente mais ou menos acompanhadas por novos depósitos, de modo que um banco só precisa de uma reserva de dinheiro modesta para cumprir bem suas promessas $^{1}$. (KRUGMAN, 2008, p. 1, tradução livre).

Agindo como intermediários financeiros, os bancos captam recursos dos poupadores, deixam uma reserva legalmente estabelecida pelo Banco Central, conhecido como recolhimentos compulsórios, e emprestam aos tomadores de empréstimos. Sistema que se multiplica por várias vezes, devido ao efeito multiplicador do crédito (ASSAF NETO, 2011, p. 39).

Forma-se assim o mercado de crédito em que a instituição financeira recebe recursos do poupador, funding da operação de crédito, obrigando-se a devolver acrescido de juros. Com esse capital, a instituição realiza operações de empréstimo e financiamento a tomadores de recursos, cobrando um valor superior aos juros pago ao poupador, devendo ficar com uma reserva do valor tomado do poupador, os já citados recolhimentos compulsórios. As instituições bancárias têm um ambiente propício para alavancar quantias monetárias, gerando empréstimos, que por sua vez, retornam às instituições em forma de novos depósitos (ASSAF NETO, 2011, p. 63).

Dessa forma surge a moeda escritural, sendo esta a principal razão das falências bancárias em função da corrida aos bancos, eis que esta é fictícia, ou seja, é uma criação do sistema financeiro instituída pelos bancos.

\footnotetext{
Normally, banks satisfy both desires: depositors have access to their funds whenever they want, yet most of the money placed in a bank's care is used to make long-term loans. The reason this works is that withdrawals are usually more or less matched by new deposits, so that a bank only needs a modest cash reserve to make good on its promises.
} 
Quando uma grande quantidade de poupadores resolve resgatar seus valores depositados, a moeda escritural é tão grande em relação à moeda emitida que esta é insuficiente para arcar com os depósitos existentes, gerando um déficit no balanço de pagamento dos bancos. O que ocasiona esse fenômeno?

A fim de explicar como ocorre a corrida aos bancos, algumas teorias foram criadas. Passa-se a explanar a respeito destas para compreender o impacto e a relação das decisões tomadas pelos agentes econômicos em relação à histeria financeira, e, de forma complementar, demonstra-se alguns casos análogos, que apesar de não serem especificamente voltados ao fenômeno estudado comportam-se de forma semelhante.

\section{O EFEITO CASCATA E AS PLANK ROADS}

James Surowiecki em seu livro Wisdom of Crowd (SUROWIECKI, 2005, p. 52) traz um interessante caso envolvendo uma série de tomadas de decisões entre agentes econômicos. O caso aproxima-se da ideia da histeria coletiva, pois envolve a tomada de decisão e um conjunto de informações em um âmbito coletivo. Para ele a informação não está nas mãos de uma só pessoa, ela se dispersa por várias. Ele percebeu que em determinadas situações, a tomada de decisões em um âmbito coletivo teria melhores efeitos do que se for analisar individualmente a tomada de decisão de cada participante. Todavia, o inverso também é aplicável, por vezes a coletividade equivoca-se em determinadas decisões.

Ele relata que no começo do século XIX, com o rápido crescimento nos Estados Unidos, a população interiorana começou a sofrer com problemas de estradas que ligavam pequenas cidades ou vilarejos ao centro das cidades maiores. "Elas tinham fundações superficiais, quando tinham, e problemas de drenagem [...] Sua superfície formava sulcos de lama em dias de chuva e sulcos de poeira em dias secos; viajar era extremamente lento e desgastante em veículos e em animais". ${ }^{2}$ (KLEIN; MAJESTIKI apud SUROWIECKI, 2005, p. 52, tradução do autor) Naquela época, um engenheiro chamado George Geddes achou que tivesse descoberto a solução utilizando um sistema chamado plank road, que consistia em pranchas de madeira colocadas sobre duas linhas de madeira, por todo o caminho.

\footnotetext{
2 Texto original: "They had shallow foundations, if any, and were poorly drained [...]. Their surfaces were muddy ruts in wet weather, dusty ruts in dry; travel was slow and extremely wearing on vehicles and on the animals that drew them."
} 
As plank roads eram financiadas por dinheiro privado e deveriam durar tempo suficiente para serem rentáveis. George Geddes acreditava que o seu tempo de vida seria de oito anos, o suficiente para obter o retorno do investimento. Em 1846 ele convenceu alguns investidores em Nova York a investirem na primeira empresa de plank road. Inicialmente, as estradas de madeira foram um sucesso, foram implantadas no estado de Nova York e logo para outras regiões dos Estados Unidos. Em uma década foram criadas 352 empresas de plank road em Nova York e mais de 1000 em todo o país.

Todavia, o negócio criado foi uma ilusão, conforme relata o autor (SUROWIECKI, 2005, p. 52), a estrada que seria para durar 8 anos não chegava a 4 anos. Em meados de 1850 ficou claro que a plank road não era a solução do problema das estradas americanas, porém sua operação perdurou até 1880, até o fim da Guerra Civil, quando quase todas foram abandonadas.

$\mathrm{O}$ autor relata que esse fenômeno é denominado pelos economistas de "Informação em Cascata" (Information Cascade), ou seja, quando a primeira empresa de plank road obteve no curto prazo um sucesso, acreditando que tinha solucionado o problema das estradas, a informação se propalou rapidamente e outras empresas começaram a investir no setor. Utilizando o modelo dos economistas Sushil Bikhchandani, David Hirshleifer e Ivo Welch, Surowiecki (2005, p. 53) explica da seguinte forma: imagine dois restaurantes, um Indiano e um Tailandês, e um grupo grande de pessoas que podem escolher comer em um desses dois estabelecimentos. Objetivamente, o Indiano é melhor. Cada pessoa do grupo recebe uma informação de qual restaurante é melhor, todavia de uma maneira incompleta. Pode ocorrer da informação incompleta levar algumas pessoas a acharem que o restaurante Tailandês é melhor, quando na verdade não é. Para completar as informações, as pessoas irão olhar o que as outras estão fazendo.

O problema começa quando as decisões são feitas em sequência, as primeiras pessoas começam a ir a um dos dois restaurantes e as demais começam a segui-las. Poderia ocorrer de esse primeiro restaurante ser o Tailandês, que não é o melhor entre os dois. Sendo as informações incompletas, as pessoas poderiam ao ver o restaurante Tailandês mais cheio do que o Indiano, optar por este, e a informação em cascata aumentaria ainda mais o erro ocorrido. Dessa forma, o ponto fundamental dessa teoria é que após certo tempo tornase racional para o indivíduo parar de agir conforme seu próprio conhecimento, sua informação, e passar a seguir as ações de outros indivíduos. 
Apesar do modelo exemplificativo não envolver instituições financeiras e o mercado de crédito, ele traz um raciocínio lógico e demonstrativo, em que a tomada de decisão de cada indivíduo depende não só do seu nível de conhecimento, mas de todo o sistema em que ele está envolvido. Nesse caso, a coletividade comporta-se de uma maneira uniforme, consequência do agir em cascata de cada indivíduo nela inserido.

\section{EFEITO MANADA E CASCATA DE DISPONIBILIDADES}

Outro modelo que tenta desvendar a origem da histeria financeira é chamado de efeito manada (herd behavior). O economista Abhijit V. Banerjee criou um modelo econômico relacionando a tomada de decisão com informações, algo similar ao já exposto efeito cascata. Todavia, conseguiu transformar para meios matemáticos a probabilidade de cada pessoa receber um sinal verdadeiro ou não, o que assumindo uma distribuição uniforme e, portanto, resultando em uma informação assimétrica, supondo como falso o sinal.

O modelo também seria sequencial, no qual o primeiro indivíduo escolheria aleatoriamente a sua decisão; o segundo indivíduo também escolheria aleatoriamente sua decisão, porém, seria permitido observar a escolha do primeiro indivíduo e beneficiar-se com sua decisão. Todavia, o segundo indivíduo não saberia se o primeiro indivíduo teria o sinal verdadeiro. O restante do jogo ocorreria da mesma forma, os demais indivíduos tomariam sua decisão, observando as decisões passadas de outros indivíduos, mas conhecendo apenas o seu sinal (BANERJEE, 1992, p. 7).

O que o modelo indica é que, diferente de Smith, o equilíbrio se dará utilizando seu próprio conhecimento (sinal) e as informações do restante dos indivíduos ${ }^{3}$. Entretanto, quando o próximo indivíduo não tiver o seu próprio sinal, seguiria as decisões conforme outros indivíduos. "A estratégia de cada indivíduo é uma regra de decisão que nos conta, para cada possível história, o que cada pessoa irá escolher"4 (BANERJEE, 1992, p. 8, tradução livre). Ocorre o efeito manada quando os indivíduos abandonam seus sinais e passam a seguir os outros indivíduos, acreditando que eles estão certos.

Esse modelo explica certos tipos de fenômenos ocorridos no mercado financeiro, quando ocorrem os saques em bancos pelos indivíduos na chamada histeria financeira.

\footnotetext{
3 Ver Teoria dos Jogos e a Economia de Cooperação em Mankiw (2001, p. 358-366).

${ }_{4}$ Texto original: Each person's strategy is a decision rule that tell us for each possible history what that person will choose.
} 
A última grande crise financeira que o mundo presenciou em 2008 não foi diferente. Da mesma forma como outros casos já ocorridos, a crise de 2008 foi antecedida por anos de uma relativa riqueza em que o sistema financeiro foi alheio às intervenções do Estado. Um sistema de empréstimos bancários baseado no setor imobiliário criou os problemas para a eclosão da crise. Instituições de crédito do setor financeiro liberaram no mercado, para compra de imóveis, o empréstimo subprime de alto risco e rentabilidade alta para essas instituições. Os empréstimos eram securitizados em bancos de investimentos com outros tipos de empréstimos, criando complexos derivativos, e vendidos para investidores. Desta forma os pacotes de securitização continham diversos empréstimos impagáveis, o que acarretou em um prejuízo aos investidores e a toda a cadeia, atingindo, inclusive, os tomadores dos empréstimos que perderam seus imóveis.

A crise atingiu desde bancos comerciais, instituições de seguros até as caixas de depósitos. José Eduardo Faria (2011, p. 21) acrescenta outros fatores que contribuíram para desencadear a crise como:

[...] das arbitragens com taxas de juros e taxas de câmbio, da opacidade de novos tipos de operações e fundos de investimento, dos níveis elevados e não controlados de alavancagem, do conflito de interesse de agências de classificação de risco, das políticas de remuneração que incentivam os executivos financeiros a uma excessiva exposição de risco e da coexistência de instituições regulamentadas e outras instituições em mercados com pouca ou sem nenhuma regulamentação.

A crise não se restringiu ao setor financeiro, outros setores da economia também sofreram suas consequências, todavia o ponto nevrálgico da crise foi eminentemente financeiro, o que gerou a histeria financeira, levando milhões de cidadãos a sacarem seus depósitos. Dezenas de instituições financeiras faliram em todo o mundo, desaparecendo bilhões em valores monetários. Em quase todos os centros financeiros mundiais os governos foram obrigados a intervir e injetar bilhões de dólares na economia.

Como se vê, a histeria financeira não surge como um fenômeno auto referencial, mas é uma reação da população a algum evento pretérito, seja econômico, social ou político. O estudioso da área da economia comportamental que analisa a tomada de decisão, Daniel Kahneman (2012, p. 170), vencedor do Prêmio Nobel, cita em seu trabalho o estudo de Paul Slovic acerca das peculiaridades do julgamento do risco dos seres humanos. Para ele os cidadãos 
comuns são "[...] orientados pela emoção mais do que pela razão, facilmente influenciados por detalhes triviais e inadequadamente sensíveis às diferenças entre probabilidades baixas e insignificantemente baixas".

Isso é uma forma de demonstrar que pessoas respondem a incentivos, ou seja, as condições do meio em que os indivíduos vivem influenciam diretamente a tomada de decisão destes. A título de exemplo, "[...] quando os formuladores de políticas públicas não levam em conta como suas medidas afetam os incentivos, acabam gerando resultados não-desejados" (MANKIW, 2001, p. 7), ou até mesmo declaração enganosa como no mês de maio de 2013, em que o programa do governo "Bolsa Família" viria a acabar. O presidente da Caixa Econômica Federal, instituição bancária que repassa os valores do programa, Jorge Fontes Hereda, admitiu que o banco passou informação equivocada sobre a liberação de todos os pagamentos do Bolsa Família na véspera dos boatos que levaram mais de 900 mil pessoas às agências e caixas eletrônicos para sacar os benefícios. Ocorreram filas extensas em todo o país, provocado por um pânico entre os beneficiários, apesar de desmentido os boatos logo após o incidente (COMISSÃO..., 2013).

Kahneman (2012, p.185) trouxe em seu livro a teoria de Cass Susntein a qual se encaixa ao caso narrado. Ele chama de "cascata de disponibilidade" um conjunto de eventos autossustentáveis, nos quais uma notícia na mídia em relação a algum evento pode desencadear um pânico coletivo e uma ação governamental. Ela é autossustentável, pois é uma reação emocional que chega às mídias, sem a necessidade de uma fonte segura, e, consequentemente, potencializa-se ainda mais a preocupação e o envolvimento gerado. Para ele, esse ciclo torna-se ainda mais rápido quando outras instituições se envolvem no caso, aumentando o fluxo de notícias preocupantes. E por mais que especialistas ou membros do governo tente demonstrar a falácia ou o exagero da informação, o público tende a desacreditar nos especialistas, como se fosse uma forma do governo acobertar a situação. Nas palavras do autor, "[...] isto é uma cascata de disponibilidades: um não evento que é exagerado pela mídia e o público até inundar nossas telas de tevê e se tornar a única coisa sobre o qual está todo mundo falando" (KAHNEMAN, 2012, p. 185).

Em 2012 ocorreu algo semelhante nos países da Europa, Grécia e Espanha, quando surgiram rumores que esses países realizariam um semi congelamento das contas bancárias. Cidadãos de todo o país foram aos bancos sacar seus depósitos (RIBEIRO, 2013). Apesar dos bancos não terem sido a causa da crise econômica ocorrida nesses países à época, foram as instituições atingidas 
diretamente pelas suas conjunturas econômicas. Com um agregado de políticas governamentais, informações falaciosas e a crise pela qual esses países passavam, muito de seus depósitos foram sacados e enviados a instituições financeiras de outros países que passavam por melhores condições econômicas. Assim a crise foi agravada, pois o capital migrou de regiões problemáticas para as de melhores condições, e a histeria financeira atingiu a maior parte do país.

\section{O PAPEL DO ESTADO E A REGULAÇÃO FINANCEIRA}

Viu-se que o mercado financeiro é um complexo sistema sensível a mudanças na ordem econômica. $\mathrm{O}$ antigo modelo liberal, que no final do século $\mathrm{XX}$ voltou a ganhar forças nesse setor, foi o responsável pela grande crise surgida no final da década de 2000, sendo a representação de que a atuação do segmento desregulamentado não seria suficiente para suprir as necessidades surgidas em meio à crise.

Novamente, o Estado necessitou tomar medidas em âmbito macroeconômico, intervindo no domínio econômico, visando não tanto o objeto do Estado social do pós-guerra, mas a própria configuração do sistema financeiro, do qual o sistema capitalista necessita para sobreviver. Tem-se assim, a regulação econômica, no sentido explicado por Sundfeld (2006, p. 23), em que "[...] o Estado não assume diretamente o exercício da atividade empresarial, mas intervém enfaticamente no mercado utilizando instrumento de autoridade".

A regulação econômica se configura, dessa forma, em um conjunto de medidas normativas de caráter abstrato e concreto, com intuito de controlar o comportamento dos agentes econômicos. Para o setor financeiro, esses instrumentos, são aplicados mais no sentido de supervisão, na forma indireta de intervenção, com o escopo de fiscalizar e determinar regras que limitem o agir e a alavancagem irresponsável das instituições financeiras. Nesse contexto, vale destacar dois dispositivos normativos oriundos do direito econômico: os instrumentos e os mecanismos de regulação.

Os instrumentos de regulação podem ser percebidos como processo normativo, fiscalizador, incentivador, planejador e mediador da atividade econômica, em que o Estado presta desde atividades do efetivo exercício do poder de polícia até estímulos em forma de fomento, incentivado diretamente determinadas atividades (FIGUEIREDO, 2011, p. 113).

Já os mecanismos de regulação compreendem uma espécie interventiva de cunho contratual, determinado em lei específica em certos mercados, em 
que os agentes econômicos têm a faculdade de controlar a oferta e demanda de seus produtos, quando previamente autorizados pelo ente regulador (FIGUEIREDO, 2011, p. 113).

Esses mecanismos reguladores apresentam funções mais específicas que os instrumentos de regulação, visto o caráter concreto e aplicável especificamente ao setor visado. "Na prática, estes mecanismos têm como objetivo controlar o uso dos serviços prestados aos consumidores pelos agentes econômicos” (FIGUEIREDO, 2011, p. 114). No caso da política interna dos países, os bancos centrais encerram fundamental papel na elaboração desses mecanismos, utilizando políticas normativas que lhe são cabíveis para aplicar a cada setor.

Contudo, o complexo sistema internacional exige que outros dispositivos sejam criados, pois a regulação interna de cada país está adstrita às suas fronteiras. Nesse sentido, surgiram tratados e órgãos internacionais para tratar do assunto, como o Comitê para Práticas de Supervisão e Regulamentação Bancária do Banco de Compensações Internacionais (BIS), conhecido como Comitê da Basiléia. Trata-se de órgão formado por países do $\mathrm{G} 10^{5}$, para " [...] formulações de recomendações sobre o controle dos riscos a que se submetem as instituições bancárias, num ambiente de acentuada internacionalização das relações econômicas" (NEIVA, 2008, p. 2).

Essa instituição entendeu que o mercado financeiro está suscetível a diversos riscos, como o de liquidez, o dos bancos tornarem-se insolventes quando e se ocorrer o efeito manada. Neiva (2008, p. 76) analisa essa conjuntura como risco sistêmico, em que os formuladores de políticas lançam mão de dois instrumentos de regulação para inibir que a histeria financeira ocorra: o seguro de depósitos e a função de emprestador de última instância, desempenhada pelo banco central.

Faria (2011, p. 31) descreve que em uma crise sistêmica exige-se muito mais do que uma justaposição de interesses de Estados nacionais.

[...] requerem ações multilaterais coordenadas, que vão além dos tradicionais acordos de cooperação intergovernamental, e novas estruturas institucionais e regulações de alcance transnacional, cuja concepção, implantação e atuação efetiva dependem de novas relações de força.

${ }_{5}$ O Grupo dos Dez é uma organização internacional que reúne representantes de onze economias desenvolvidas. 
Discute-se, dessa forma, não só instrumentos ou mecanismos de regulação, mas também institutos internacionais com o propósito de reestabelecer a disciplina sobre os mercados financeiros, como a criação de uma agência supervisora internacional. Faria $(2011$, p. 3) identifica o órgão "[...] como um capaz de exercer o papel de market maker global".

Embora o direito procure diversos instrumentos ou mecanismos de intervenção, ainda não existe um consenso se o controle externo deve se feito de maneira impositiva ou por meio de incentivos (NEIVA, 2008, p. 76). O fato é que o sistema financeiro é sensível a mudanças na ordem econômica, cabendo ao direito a função de desempenhar o principal papel, de instrumento regulador.

Evidente que o risco sistêmico é consequência da própria falha na estrutura do mercado financeiro. A evolução dos ativos, pela maioria das vezes, não vem acompanhada pela atualização da própria estrutura do sistema, gerando desequilíbrios. Nessa senda, são necessárias para a atenuação desse risco não só o direito, mas também as instituições responsáveis em aplicar esse direito. As agências regulatórias são o típico exemplo de instituições responsáveis no controle e fiscalização. Contudo são as medidas macroeconômicas de políticas interventivas as responsáveis pela regulação estrutural do sistema financeiro.

A dinâmica das transformações no sistema financeiro é extremamente veloz, novas formas de se criar riqueza, de instrumentos fictos, surgem antes que o formulador de política possa garantir a segurança jurídica necessária. Relevam-se, ainda, grupos de interesses de alto poderio econômico, os quais têm grande influência no sistema normativo que abrange esse meio. Aimplicação desses grupos de interesses seriam políticas públicas voltadas a atender anseios de grandes corporações. Parte dos poderes legislativos e executivos poderia estar voltada a atender certos interesses em troca de benefícios eleitorais. Dessa forma, não existe um raciocínio matemático de estancamento da sangria gerado por um setor em desequilíbrio, mas um conjunto de premissas aplicáveis nessa tentativa, pois o sistema financeiro não estaria desvinculado da política no sentido pragmático.

\section{CONSIDERAÇÕES FINAIS}

A Histeria Financeira ocorre em um espaço pequeno de tempo e representa toda (des)ordem de uma coletividade. A corrida aos bancos, ou o efeito manada como alguns economistas gostam de dizer, decorre de informações propagadas na população e repercute no mercado financeiro. Essas informações 
podem surgir em cascata, como o exemplo dos restaurantes, ou da observância de uma crise eminente, como o caso da crise de 1929 . O certo é que essa histeria surge em pouco tempo, toma proporções gigantescas, e as instituições bancárias não conseguem arcar com o passivo formado levando-as à falência.

Decorrente da racionalidade humana, o indivíduo reage a incentivos, e suas tomadas de decisões particulares visam à maximização de sua utilidade, mesmo que essa possa causar um dano coletivo. Os efeitos são comparados a uma manada em que uma cadeia de eventos da população cria a histeria financeira. Nessas situações, o mercado por si não é capaz de resolver, devendo a mão do Estado intervir e amenizar os efeitos por ela gerados.

A globalização aumenta o potencial nocivo da histeria gerada e o efeito dominó das falências das instituições financeiras atravessa continentes, pois as informações são instantaneamente repassadas. O fato é que a histeria surge decorrente de outros fatores, como as crises econômicas ou até informações falaciosas propagadas pela mídia, por isso é difícil precisar um controle efetivo para abafa-la em seu início.

O Estado de Direito, apesar das incertezas que esse ambiente reproduz, não está alheio às nuances inerentes ao sistema financeiro, pois a história já demonstrou que a estrutura desse sistema é sensível a notícias ou ataques especulativos. Vê-se que, nos tempos atuais, a proporção da histeria financeira envolve muito mais do que um Estado soberano, mas toda a comunidade internacional. O efeito dominó de uma manada trará consequências potencializadas, e, sempre, o lado mais fraco sofrerá às consequências.

A normatização do setor deve ser regulada de forma a atenuar os impactos gerados por crises do mercado. Os agentes envolvidos no mercado financeiro não podem agir livremente, sem a intervenção Estatal. Agências reguladoras devem desempenhar um papel mais ativo no sentido de fiscalização e controle. A volatilidade dos ativos financeiros necessita de regras mais rígidas. Mecanismos de controle que denotem maior transparência são imprescindíveis. No âmbito internacional, os tratados devem ser firmados no sentido de prevalecer a cooperação financeira. Necessário assim se faz o surgimento de regras coordenadas de comportamento, uniformizando e submetendo normas internas aos acordos internacionais.

Após a crise de 2008 tornou-se dominante no pensamento econômico que o sistema financeiro não pode agir livremente. Imperioso é criar políticas de intervenção no âmbito interno e externo, pois as instituições financeiras atuam 
em diversos países e, dessa forma, aprenderam as vantagens de utilizar o fluxo de capital entre eles. Políticas essas que não serão absolutas, pois as crises no sistema financeiro sempre existirão, todavia essa regulamentação é imprescindível, mesmo como uma forma de atenuar uma futura crise.

\section{REFERÊNCIAS}

ASSAF NETO, Alexandre. Mercado financeiro. 10. ed. São Paulo: Atlas, 2011.

BANERJEE, Abhijit V. A simple model of herd behavior. The Quarterly Journal of Economics, Oxford, v. 107, n. 3, p. 797-817, 1992. Disponível em: <http://www.jstor.org/stable/2118364>. Acesso em: 27 out. 2013.

COMISSÃO do senado irá convidar presidente da CEF para falar sobre bolsa família. 2013. Disponível em: <http://noticias.uol.com.br/politica/ultimasnoticias/2013/06/11/comissao-do-senado-ira-convidar-presidente-da-cef-parafalar-sobre-bolsa-familia.htm>. Acesso em: 19 jun. 2013.

FARIA, José Eduardo. O estado e o direito depois da crise. São Paulo: Saraiva, 2011.

FIGUEIREDO, Leonardo V. Lições de direito econômico. Rio de Janeiro: Forense, 2011.

GALBRAITH, John K. The great crash, 1929. [S. 1.]: Mariner Books, 2009.

KAHNEMAN, Daniel. Rápido e devagar: duas formas de pensar. Tradução de Cássio de Arantes Leite. Rio de Janeiro: Objetiva, 2012.

KRUGMAN, Paul. Partying like it's 1929. The New York Times, New York, 21 Mar. 2008. Disponível em: <http://www.nytimes.com/2008/03/21/ opinion/21 krugman.html?_r=0>.Acesso em: 27 out. 2013.

MANKIW, N. G. Introdução à economia: princípios de micro e macroeconomia. 2. ed. Rio de Janeiro: Campus, 2001. 
NEIVA, Micheline M. Análise jurídica do segundo acordo da basiléia: a regulação do mercado bancário internacional por meio de instrumentos de soft law e sua legitimidade democrática. 2008. Dissertação (Mestrado em Direito) - Faculdade de Direito da Universidade de Brasília, Brasília, 2008.

RIBEIRO, Marcelo. Corrida bancária na Europa remete à Argentina. Disponível em: $<$ http://www.brasileconomico.ig.com.br $>$. Acesso em: 26 out. 2013.

SUNDFELD, Carlos Ari. Introdução às agencias reguladoras. In:

MALHEIROS, Carlos Ari (Org.). Direito administrativo econômico. São Paulo: Sundfeld, 2006. p. 23-27.

SUROWIECKI, James. The wisdom of crowds. New York: Anchor Books, 2005.

TROTSKI, Leon. Os Estados Unidos após a crise de 1929. 1936.

Disponível em: $<$ http://www.dominiopublico.gov.br/download/texto/ ma000072.pdf/>.Acesso em: 27 out. 2013.

Artigo recebido em: 20/10/2015 Aprovado para publicação em: 30/10/2015

Como citar: TAKADA, Thalles Alexandre; MUNIZ, Tânia Lobo. Risco Sistêmico E A Histeria Gerada No Mercado Financeiro Global Revista do Direito Público. Londrina, v.10, n.3, p. 75-90, set/dez.2015. DOI: 10.5433/ 1980-511X.2015v10n3p75. ISSN: 1980-511X. 